\title{
Alginate/Bioactive Glass Beads: Synthesis, Morphological and Compositional Changes Caused by SBF Immersion Method
}

\author{
Hermes de Souza Costa ${ }^{a *}$ (1), Mariane Rezende Dias ${ }^{a}$ \\ ${ }^{a}$ Centro Federal de Educação Tecnológica de Minas Gerais (CEFET-MG), Departamento de \\ Engenharia de Materiais, Belo Horizonte, MG, Brasil.
}

Received: December 24, 2020; Revised: March 27, 2021; Accepted: May 18, 2021

\begin{abstract}
Composites of biodegradable polymers/bioactive glasses (BG) are of particular interest in bone repair, where ceramic phase can improve osteogenic features. This work reports the development of organic-inorganic beads based on alginate prepared by incorporating at polymer suspension different contents $(25,50$ and $75 \mathrm{wt} \%$ with respect to alginate) of $\mathrm{BG}$ present at precursor solution, whose system $\left(\mathrm{SiO}_{2}-\mathrm{CaO}-\mathrm{P}_{2} \mathrm{O}_{5}\right)$ was obtained by hydrolysis of both tetraethoxysilane (TEOS) and triethylphosphate (TEP) alkoxides, molar ratio TEOS:TEP of 1:0.1317, and which calcium source came from the same cold $\mathrm{CaCl}_{2}$ solution used to gelling the hybrids. Beads were synthesized by extruding mixtures, drop by drop, in $\mathrm{CaCl}_{2}$ solution. Were also investigated the behavior resulting upon soaking of hybrids into SBF. Samples were characterized by SEM, ATR-FTIR, TGA and XRD analysis. Results indicated decrease in spheres size with increase of glass and presence even pos-immersion, of $\mathrm{Si}, \mathrm{Ca}$ and $\mathrm{P}$ associated to $\mathrm{BG}$ phase.
\end{abstract}

Keywords: Alginate, bioactive glass, microspheres, composite, biomaterials.

\section{Introduction}

Bioactive glass particles, when in contact with body fluids, are able to bond to living bone through the formation of a surface layer of hydroxyapatite (HAp), as a result of their high reactivity in aqueous media. Moreover, the products of the ionic dissolution of bioactive glasses ( $\mathrm{Si}$ and $\mathrm{Ca}$ ) can lead to favorable intracellular and extracellular responses, actively stimulating bone formation ${ }^{1-6}$. Another advantage of bioactive glasses includes their antibacterial properties against a wide range of pathogenic bacteria ${ }^{7,8}$.

Hench identified the compositional limits for bone and soft tissue bonding in the $\mathrm{SiO}_{2}-\mathrm{Na}_{2} \mathrm{O}-\mathrm{CaO}-\mathrm{P}_{2} \mathrm{O}_{5}$ glass system, showing the best composition as $45 \% \mathrm{SiO}_{2}-24.5 \% \mathrm{Na}_{2} \mathrm{O}-24.5 \% \mathrm{CaO}-6 \% \mathrm{P}_{2} \mathrm{O}_{5} \mathrm{wt} \%{ }^{1,9}$. Over the course of the years, several other types of bioactive glasses were synthesized with silicon varying from 21 to $75 \mathrm{wt} \%$, for materials synthesized by conventional meltquenching ${ }^{10}$. As stable bioactive gel-glass could be made by sol-gel processing, bioactivity in SBF was demonstrated for gel-glass compositions up to $90 \% \mathrm{SiO}_{2}{ }^{9,11}$.

The bioactivity of bioactive glass is not an absolute concept determined only by the composition, but is also affected by the size and shape of the material ${ }^{12}$.

When compared with microparticles, nanoparticles have a significantly higher surface area and this drastically changes the material characteristics, such as surface energy, wettability, surface topography, and surface chemistry. Furthermore, studies have shown that nanoscale materials have higher biocompatibility ${ }^{13}$.

A problem that can be observed with the use of very fine-grained materials to aid in the formation of bone tissue,

* e-mail: hermes@cefetmg.br is associated with its degradation, where it can found that the use of sol gel derived silica nanoparticles show faster surface dissolution, associate with high area and reactivity ${ }^{14}$.

Some actual bone substitutes can be found in different forms, as example in block or granular form, which they are then used to fill the bone defects. However, each form is associated with problems. The block form tends to have a low filling factor ${ }^{15}$ and therefore requires curettage or other related measures at the filling site ${ }^{16}$ and cells exist only in the area near the surface of scaffolds ${ }^{17}$. With the granular form, variations tend to arise in filling density, and pore maintenance is difficult ${ }^{16}$. Nevertheless, recent studies pointed out the favorable properties with use of granules ${ }^{15,17,18}$, with some systems been obtained by adding powders at micrometer scale on polymeric materials ${ }^{6}$. As result scaffolds can be fabricated by accumulating spheres to create a porous network and act as osteoconductive material ${ }^{15}$.

Another advantage of bioactive beads used as filler have been demonstrated by acquire a macropore architecture, where the convex arc of beads was markedly beneficial for bone formation in comparison of pore architecture with concave arc shape. The suggested mechanism for scaffolds osteogenic activity was attributed to which convex surfaces were more conductive to liquid flow and cell growth ${ }^{19}$. In addition, adjusting the packing of the beads can promote porosity and pore size compatible with cell proliferation and blood vessel migration ${ }^{20}$.

If osteoblast-like cells can adhere and grow at the surface of polymers based microparticles where these substrates could be used for: (i) nonload bearing applications or as part of a 3D-construct; (ii) cultivating anchorage-dependent cells 
in a dynamic bioreactor and (iii) encapsulating bioactive molecules in the microparticles and simultaneously growing cells at the surface of the microparticles that would release encapsulated growth factors to stimulate proliferation and differentiation of adherent cells ${ }^{21}$.

Thus, produce polymer in hydrogels form associate with a bioactive glass phase, it can bring additional functionalities ${ }^{22}$, including crosslinking which was shown to affect the elasticity, Young's modulus, and the cell adhesion ${ }^{23}$.

As example for polymer that is able to produce hydrogels we have alginate ${ }^{24,25}$, which can stablish crosslink from its $\mathrm{G}$ blocks ${ }^{26}$. Due to its biocompatibility, biodegradability, ability to chelate calcium ions and to absorb large amounts of water, alginate has been widely used in a variety of biomedical applications including tissue engineering and drug delivery ${ }^{27-29}$.

In regard with hybrid hydrogels, one of the approaches to induce crosslinking of anionic polysaccharide including the so-called internal gelation, employing such inorganic fillers as $\mathrm{Ca}^{2+}$ ions which crosslink the polymer suspension leading to the formation of a homogeneous hydrogel network ${ }^{27,28}$. Another inorganic compound, that can be used as a source of $\mathrm{Ca}^{2+}$ ions for internal gelation, as well as for source of silicon groups are the bioactive glasses ${ }^{8,30}$.

In this context, this work presents the production and characterization of hybrid microparticles based on alginate and bioactive glasses it can be able to promote polymeric structure blended with a dispersed inorganic phase of bioactive glass at nanometric scale (of Si-Ca-P sol-gel system), where the chemical composition and morphology can promote a significant effect on the bioactive properties of material. In addition, we hypothesize that production of spheres by controlling its diameter can be able to control the pore size of beads accumulated as $3 \mathrm{D}$ scaffolds in bone defect sites, and fulfill requirements for osteoconduction and vessel migration. Moreover, they can regulate the release of glass degradation products in order to increase bioactivity, compatible with the time required in the process to repair the calcified tissues. Finally, samples were kept in SBF following by morphological and chemical characterization.

\section{Experimental}

\subsection{Preparation of hybrid samples}

The processing route used for synthesizing the organicinorganic hybrids beads was based on sodium alginate and sol-gel-derived bioactive glass (BG) as illustrated in Figure 1.

To obtain the composite was used alginic acid sodium salt from brown algae, medium viscosity, supplied by Sigma Aldrich and selected considering aspects such as the molecular weight $\left(\mathrm{Mw}=100,000 \mathrm{~g} \cdot \mathrm{mol}^{-1}\right)$ and mannuronate/guluronate ratio $(\mathrm{M} / \mathrm{G}=1.56)$. Deionized water (DI-water, Millipore Simplicity) with resistivity of $18 \mathrm{M} \Omega \bullet \mathrm{cm}$ was used in glass solution preparations and distilled water in dissolution of simulated body solution (SBF).

\subsubsection{Preparation of the sodium alginate suspension (Sol 1)}

Aqueous suspension of alginate was prepared with concentration $1 \mathrm{wt}$. (\%) by dissolving the alginic acid powder
$(1 \mathrm{~g})$ in $100 \mathrm{~mL}$ of distilled water, under constant stirring, for $24 \mathrm{~h}$. The $\mathrm{pH}$ of the suspension was adjusted to $5.3 \pm 0.1$ by acetic acid $(\mathrm{AcOH})$ solution $1 \mathrm{~N}$.

\subsubsection{Preparation of the starting bioactive glass solution (Sol 2)}

The starting sol solution (Sol 2) was synthesized by mixing tetraethoxysilane (TEOS, Sigma), D.I. water, triethylphosphate (TEP, Sigma), in presence of hydrochloric acid solution 2 N. In this context the solution was obtained using reagents with sufficient amounts to reach a system of $86.5 \% \mathrm{SiO}_{2}-13.5 \% \mathrm{P}_{2} \mathrm{O}_{5} \mathrm{wt} \%$, which has the same weight ratio of $\mathrm{SiO}_{2} / \mathrm{P}_{2} \mathrm{O}_{5}$ found at $58 \% \mathrm{SiO}_{2}-33 \% \mathrm{CaO}-9 \% \mathrm{P}_{2} \mathrm{O}_{5} \mathrm{wt} \%$ system of our previous works ${ }^{31,32}$. However, in the present study, specifically regarding calcium content, the addition was achieved by crosslinker solution, with internal gelation taking place due slowly diffusion of calcium after the mixture of Sol 1 with Sol 2 to be dropped on cooled $\mathrm{CaCl}_{2}$ solution, as describe the item 2.1.3.

To obtain that glass solution, deionized water acidified with hydrochloric acid $\left(\mathrm{H}_{2} \mathrm{O} / \mathrm{H}^{+}\right)$had adjusted to $\mathrm{pH}=2$. Then solution was prepared in a separate beaker with $2.1 \mathrm{~mL}$ $\mathrm{H}_{2} \mathrm{O} / \mathrm{H}^{+}$and $2.2 \mathrm{~mL}$ tetraethylorthosilicate (TEOS) mixed in the given order and then allowed to react for 45 minutes at ambient temperature, when $0.2 \mathrm{~mL}$ triethylphosphate (TEP) was added and reacted for a further 30 minutes. The mole ratio of $\left(\mathrm{H}_{2} \mathrm{O} / \mathrm{H}^{+}\right)$:TEOS:TEP was 12:1:0.1317 and $\mathrm{HCl}$ was added to catalyze TEOS and TEP hydrolysis.

\subsubsection{Preparation of the Alginate-Bioactive glass hybrid beads}

The compositions of hybrids for all prepared samples are shown in Table 1 . The beads were obtained using a procedure similar to the one described in our previous work ${ }^{33}$. In short, an appropriate amount of starting glass solution was added to alginate suspensions and was stirred for approximately five minutes at the temperature of $25 \pm 5^{\circ} \mathrm{C}$. Sol $1 / \mathrm{Sol} 2$ in the final solution were made up of volume ratios 1:0.33, 1:1 and $1: 3$, resulting in final volumes of about 101.5, 104.5 and $113.5 \mathrm{~mL}$, respectively. After that $10 \mathrm{~mL}$ of each mixture was introduced dropwise from a $15 \mathrm{~mL}$ syringe with a 27.5 gauge needle into $100 \mathrm{~mL}$ of an aqueous calcium chloride solution $1 \mathrm{M}$, whose container where then sealed, and cooled down to the temperature of $7 \pm 2{ }^{\circ} \mathrm{C}$ for 7 days, as diagram shown in Figure 1. These hybrids were prepared in triplicates $(n=3)$ and referred as indicated in Table 1. After synthesis all samples were submitted to dry process in a desiccator (silica gel, under vacuum) for 7 days at the temperature of $25 \pm 5^{\circ} \mathrm{C}$.

\subsection{Structural and Chemical Characterization of Hybrids}

The particle size determination of wet beads obtained was carried out using a high-resolution digital camera with

Table 1. Sample labels and composition (wt. \%) of hybrids.

\begin{tabular}{ccc}
\hline LABEL & ALGINATE (\%) & $\begin{array}{c}\text { BIOACTIVE } \\
\text { GLASS (\%) }\end{array}$ \\
\hline 100AS-0BG & 100 & 0 \\
\hline $75 \mathrm{AS}-25 \mathrm{BG}$ & 75 & 25 \\
\hline $50 \mathrm{AS}-50 \mathrm{BG}$ & 50 & 50 \\
\hline 25AS-75BG & 25 & 75 \\
\hline
\end{tabular}




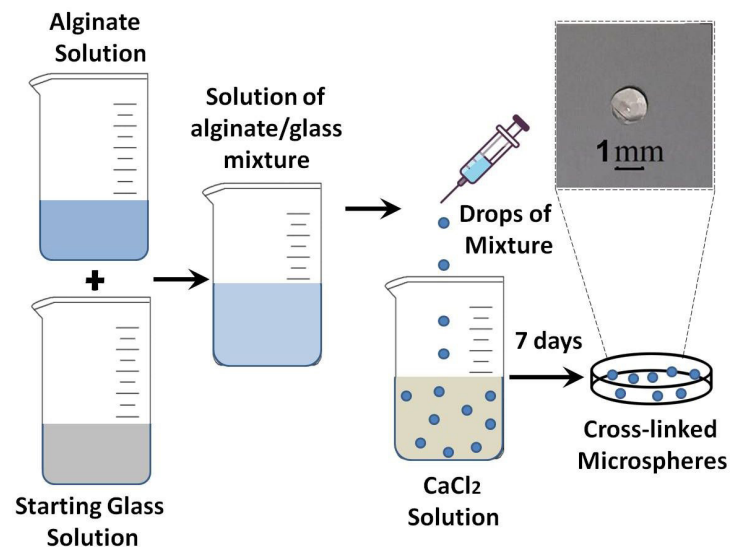

Figure 1. Scheme of the procedure to obtain Alginate/Bioactive Glass beads.

a ruler placed into the image, which was used as reference scale. The average sizes and standard deviation were determined for each formulation using images acquired by thirty beads randomly selected and evaluated by image analysis software ImageJ. Data were analyzed by one-way analysis of variance (ANOVA).

\subsubsection{Morphological analysis of particles by scanning electron microscopy (SEM)}

The SEM analysis was utilized to provide an initial qualitative evaluation of the changes on the surface structure and morphological aspects of the composite hydrogels when bioactive glass was added. The samples were dried in a desiccator (silica gel, under vacuum) at the temperature of $25 \pm 5^{\circ} \mathrm{C}$. After that the samples were covered with gold and analyzed using an SSX-550 Superscan (Shimadzu) microscope operated at $15 \mathrm{kV}$ and equipped with an energy dispersive X-ray spectroscopy (EDS) unit (Shimadzu).

Before examination, the samples were coated with a thin gold film by sputtering at a low deposition rate using a SC701 Quick Coater device (Sanyu Electron) at the current $1.5 \mathrm{~mA}$ for 3 minutes. The maximum distance between target and sample was used to avoid sample damage.

\subsubsection{Chemical characterization by FTIR spectroscopy}

Fourier transform infrared spectroscopy (FTIR) was used to characterize the presence of specific chemical groups in the Alginate/Bioactive glass hybrid samples. FTIR spectra were obtained using attenuated total reflectance (ATR, $4000-400 \mathrm{~cm}^{-1}$ using 68 scans and a $4 \mathrm{~cm}^{-1}$ resolution - Shimadzu Corporation, model IRPrestige-21), equipped with ATR accessory DuraSampl IR II, using a ZnSe crystal.

\subsubsection{Crystallinity and phase characterization by $X$-ray diffraction}

X-ray diffraction (XRD) patterns were obtained from hybrid Alginate/Biactive Glass using $\mathrm{CuK} \alpha$ radiation with $\lambda=1.54056 \AA$ (XDR 7000, Shimadzu). XRD analyses were conducted in the $2 \theta$ range from $5.0-80.0^{\circ}$ with steps of $0.02^{\circ}$. The observed peaks were identified using the "Software XPowder".

\subsubsection{Thermal analysis}

Simultaneous TG-DTA curves were obtained by using the thermal analysis equipment SII EXSTAR, model TG/DTA 7200 , using $\mathrm{N}_{2}$ as purge gas with flow rate of $90 \mathrm{~mL} \cdot \mathrm{min}^{-1}$. Heating rates of $10{ }^{\circ} \mathrm{C}\left(\mathrm{N}_{2}\right)$ was adopted using alumina crucibles between 25 and $900^{\circ} \mathrm{C}$ for the samples with masses around $5.0 \mathrm{mg}$

\subsection{Degradation upon immersion in $S B F-$ In Vitro Assay}

Bioactivity and dissolution behavior of the hybrids were studied by immersion in Simulated Body Fluid (SBF) prepared following the Kokubo protocol ${ }^{34}$ at the ion concentrations $\left(\mathrm{Na}^{+} 142.0 ; \mathrm{K}^{+} 5.0 ; \mathrm{Mg}^{2+} 1.5 ; \mathrm{Ca}^{2+} 2.5 ; \mathrm{Cl}^{-} 147.8 ; \mathrm{HCO}_{2}-4.2 ;\right.$ $\mathrm{HPO}_{4}^{2-} 1.0 ; \mathrm{SO}_{4}^{2-} 0.5 \mathrm{mM}$ ) similar to that of blood plasma. Samples of particles alginate/bioactive glass were soaked in SBF at an approved rate of $0.01 \mathrm{~g} . \mathrm{mL}^{-1}$ in sealed polyethylene containers. The flasks were place inside an incubator at controlled temperature of $37^{\circ} \mathrm{C}$ during 28 days. The samples were analyzed for periods of $0,7,14,21$ and 28 days, with the solution being refreshed every 7 days. Once was complete immersion period, the samples were rinsed gently in deionized water, and dried at $25^{\circ} \mathrm{C}$ for 48 hours in a desiccator for further characterization.

\section{Results and Discussion}

\subsection{Characterization of synthesized samples}

Biomaterials at form of beads have been used in various biomedicine-related fields, as vehicle for drug delivery system $^{35}$, carriers for cell culture in vitro ${ }^{36}$ and bead assembled system of $3 \mathrm{D}$ implant ${ }^{20}$ which spheres accumulated scaffolds can act as macropore platform. It is generally accepted that macropore size for osteogenesis should be $>100 \mu \mathrm{m}$, and for vascularization should be $300 \mu \mathrm{m}^{37,38}$.

Therefore, some studies showed beads of radius $\mathrm{R}$ packed presenting macropore size ranging from $0.73 \mathrm{R}$ to $2 \mathrm{R}$, formed by arrange of 3 and 5 spheres, respectively ${ }^{19}$. At this case it can be found that macropore size is $>600 \mu \mathrm{m}$ for beads with radius about $900 \mu \mathrm{m}$. Moreover, if spheres are arranged in hexagonal close packed, hypothetical pore radius that could fit into the tetrahedral arrange will be $0.225 \mathrm{R}$ and for octahedral arrange will be $0.414 \mathrm{R}^{39}$.

In this study the production of beads composed of alginate/bioactive glass with desired size and spherical shape were obtained for different concentration of the inorganic phase added on the polymer suspension. We note a decrease in the medium diameter size of wet beads, from $1,892 \mu \mathrm{m}$ in samples composed exclusively of alginate, to about $1,686 \mu \mathrm{m}$ for beads with larger concentrations of bioactive glass (75 wt.\%), as showed in the Table 2 .

According to ANOVA analysis there was no significant differences $(\mathrm{F}$-ratio $=3.89 ; \mathrm{p}$-value $=0.0002)$ between samples of 100AS-0BG and 75AS-25BG. In addition, ANOVA indicated significant variation in the size of all beads with more than $50 \mathrm{wt} \%$ of bioactive glass in the composition $(\mathrm{p}<0.05)$. However, all samples showed size of beads able to produce macropores associate to osteoconduction. 


\subsubsection{Scanning Electron Microscopy (SEM)}

Several reports show hydrogel beads prepared by using an extrusion method ${ }^{20,40}$, that approaches have been studied incorporating bioactive inorganic material into alginate, mainly using phosphate or silicate ${ }^{6,41}$ based bioactive inorganics. In general, the beads are obtained incorporating a small amount of inorganic powders at micrometer scale into alginate suspension $^{6,42}$. On the other hand a silica-alginate hybrid was obtained by the in-situ synthesis of silica networks via sol-gel process from (TEOS) and (APTES) precursors in an alginate matrix $^{43}$. In our proposal was used a sol-gel route introducing a solution of both silicon and phosphorus hydrolyzed alcoxides into polymer suspension prior to the gelation process aiming to produce hybrids specially in the form of beads.

The morphology of dried particles in all formulations studied could vary depending upon preparation compositions ${ }^{40}$. For samples 100AS-0BG were verified shape like pear, with one region round and narrowing towards the opposite side, but without a distinct tail, as shown in the Figure 2a.

In general, increasing the glass leads to decreasing on the polymer concentration of feed solution, which tended to increase the corrugated degree of particle surface to a more irregular shape that it departs considerably from a circle, as the raisin-like particles presented in the Figures $2 b, 2 c$ and $2 d$.

Table 2. Media, standard deviation and variance of wet particles diameter.

\begin{tabular}{cccc}
\hline Sample & Average $(\mathrm{mm})$ & $\begin{array}{c}\text { Standard } \\
\text { Deviation } \\
(\mathrm{mm})\end{array}$ & Variance \\
\hline 100AS-0BG & 1.8915 & 0.171556 & 0.029431 \\
\hline 75AS-25BG & 1.9807 & 0.178775 & 0.031960 \\
\hline 50AS-50BG & 1.7545 & 0.073830 & 0.005451 \\
\hline 25AS-75BG & 1.6859 & 0.109735 & 0.012042 \\
\hline
\end{tabular}
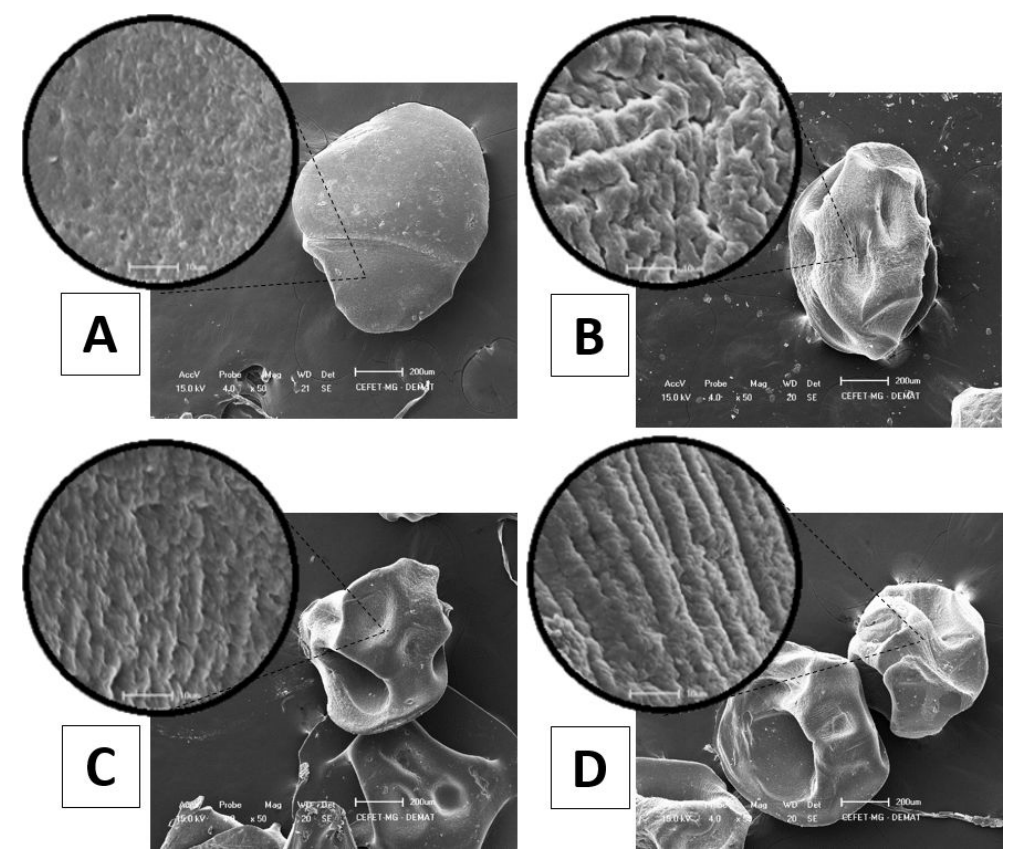

Figure 2. SEM photomicrographs (50x and 1000x magnification) of the surface of (a) 100AS-0BG; (b) 75AS-25BG; (c) 50AS-50BG and (d) 25AS-75BG samples.
The observed results for such morphological changes suggest the role of alginate as a matrix in the composite, where the structure does not remain stable during the drying process in low polymer concentrations.

Scanning electron micrographs of the microparticles are presented with magnifications in Figure 2. Alginate microparticles without glass (detail of Figure 2a) exhibited surface of smoother morphology. This finding is consistent with the data of Laia ${ }^{44}$ who demonstrated that alginate blends had a smooth and regular surface without irregular cavities.

The microparticle composites of 75AS-25BG, 50AS-50BG and 25AS-75BG samples (Details of Figure 2b, 2c and 2d) were more grooved and rough compared with alginate beads. The addition of (25 wt.\%) of bioactive glass led to surface microrelief more corrugated with striation in random orientation. The composition with (50 wt.\%) of bioactive glass had the similar morphology of ( $25 \mathrm{wt} . \%$ ), however the striation had a narrower size. A concentration of (75 wt. \%) bioactive glass showed thin and aligned grooves in a single direction.

Crosslinking the hybrids by adopting the low temperature allowed to control the gelation and permitted to extend the chelation through internal structure of beads. That it may arises due slowly diffusion of calcium to inner regions, associate with decrease in the degree of gelation at the interface of hybrids, by cooling the $\mathrm{CaCl}_{2}$ solution ${ }^{28}$.

These findings associating an increase in surface smoothness of the microparticles with an increase in degree of crosslinking may be due to the high calcium-binding capacity to alginate and bioactive glass. Where showed that the polymer nature and degree of crosslinking had a significant effect on the morphology of alginate-bioactive glass beads.

\subsubsection{Fourier transform infrared spectroscopy (FT-IR)}

Representative IR spectra of pure alginic acid powder and the hybrid particles alginate/bioactive glass (AS/BG) 
are shown in Figure 3. The broad band observed from 3100 to $3600 \mathrm{~cm}^{-1}$ in all spectra may be assigned to $\mathrm{O}-\mathrm{H}$ stretching due the strong hydrogen bond of intramolecular and intermolecular type $\mathrm{e}^{45,46}$. The band at $2850-2950 \mathrm{~cm}^{-1}$ was attributed to alkyl stretching mode $(\mathrm{vCH})$. The absorption bands at $1600 \mathrm{~cm}^{-1}$ and $1410 \mathrm{~cm}^{-1}$ decreases due to the asymmetrical and symmetrical stretching vibrations of $\mathrm{COO}^{-}$in alginate. Other typical peaks which can be associated with alginate are located at $1290 \mathrm{~cm}^{-1}$ and $1030 \mathrm{~cm}^{-1}$ both assigned to C-O-C group $^{46,47}$. In the FTIR spectrum of the hybrids with bioactive glass, presented in Figure 3, the bands related to $\mathrm{Si}-\mathrm{O}-\mathrm{Si}$ asymmetric and symmetric stretching modes are observed at approximately $1070 \mathrm{~cm}^{-1}$ and $450 \mathrm{~cm}^{-1}$, respectively ${ }^{48-50}$. Also, the vibrational band at $950 \mathrm{~cm}^{-1}$ has been credited to the presence of silanol groups $(\mathrm{Si}-\mathrm{OH})^{31}$ usually found in silica synthesized via sol-gel method. FTIR spectrum of hybrid AS/BG, presented in Figures 3c, 3d and 3e, have also presented broad bands in the frequency ranging from 3000 to $3650 \mathrm{~cm}^{-1}$ attributed to both contributions of hydroxyls (AS) and silanols (BG). In the range $1500-900 \mathrm{~cm}^{-1}$ there is a superposition of the bands derived from the bioactive glass and the alginate components.

Therefore, bands $1600 \mathrm{~cm}^{-1}$ and $1410 \mathrm{~cm}^{-1}$ are associated with the asymmetric and symmetrical stretches, respectively, of the carboxylic group $\left(\mathrm{COO}^{-}\right)^{45-47,51}$, which was intense in samples prepared with (50 wt.\%) bioactive glass and had a significant reduction for samples prepared with addition of (75 wt.\%) glass.
The bands presented in 1978, 2023 and $2160 \mathrm{~cm}^{-1}$ can be associated with carbon based gases from surrounding atmosphere on pores of samples, originated in the matrix structure during the drying process. It is also observed the presence of bands in 953, 600 and $560 \mathrm{~cm}^{-1}$ associated with the phosphate groups formed in the bioactive glass ${ }^{4,52}$.

\subsection{In vitro study in $S B F$ solution of alginate- bioactive glass hybrid beads}

\subsubsection{Hydrogels surface analysis}

The results of SEM analyses for beads samples, after immersion in SBF for 28 days, are presented in Figure 4. As a general trend the morphological aspects of hydrogels showed as corrugated for all compositions. Since the particles were produced from alginate suspensions $(1.0 \% \mathrm{~m} / \mathrm{v})$, and that the sol of glass added may resulting in mixtures with water rate above $95 \%$, it can be expected to the obtain spheres with high degree of hydration. Therefore, a high contraction for the samples should be plausible through drying process ${ }^{33,53}$. Furthermore, must also be considered that soaking time in SBF is a favorable occasion when can occur reactions between solution and materials promoting degradation of its structure ${ }^{54-56}$

Moreover, immersion in SBF permits to evaluate the ability of ions to precipitate on the surface of particles ${ }^{34}$, which was verified for all samples. Even alginate samples showed regions with precipitations, although less prominent,

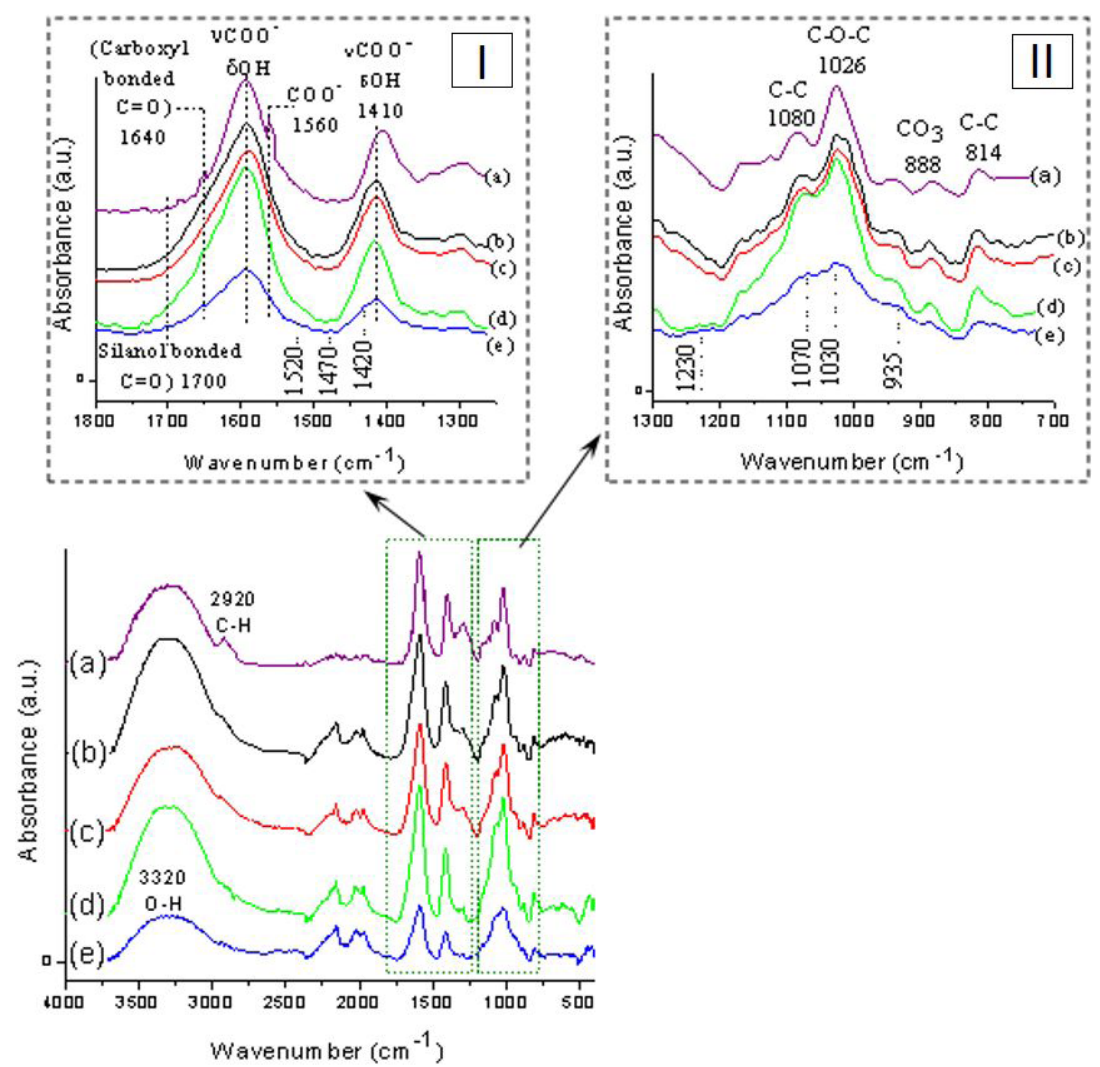

Figure 3. FTIR spectra of surfaces of (a) alginic acid sodium salt; (b) 100AS-0BG; (c) 75AS-25BG; (d) 50AS-50BG and (e) 25AS-75BG. Details of FTIR spectra for selected regions: (I) - (1800-1300 $\left.\mathrm{cm}^{-1}\right)$ and (II) - (1300-700 $\left.\mathrm{cm}^{-1}\right)$ showed in rectangles. 


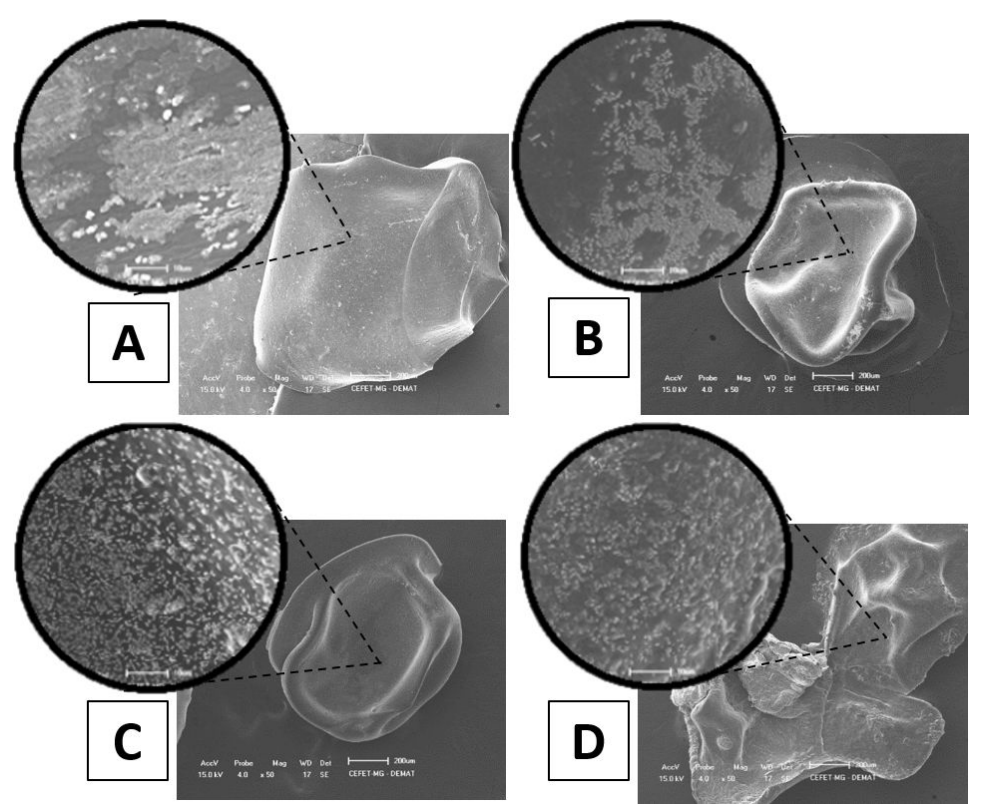

Figure 4. SEM photomicrographs (50x and 1000x magnification) of the surface of (a) 100AS-0BG; (b) 75AS-25BG; (c) 50AS-50BG and (d) 25AS-75BG samples after 28 days of immersion on SBF.
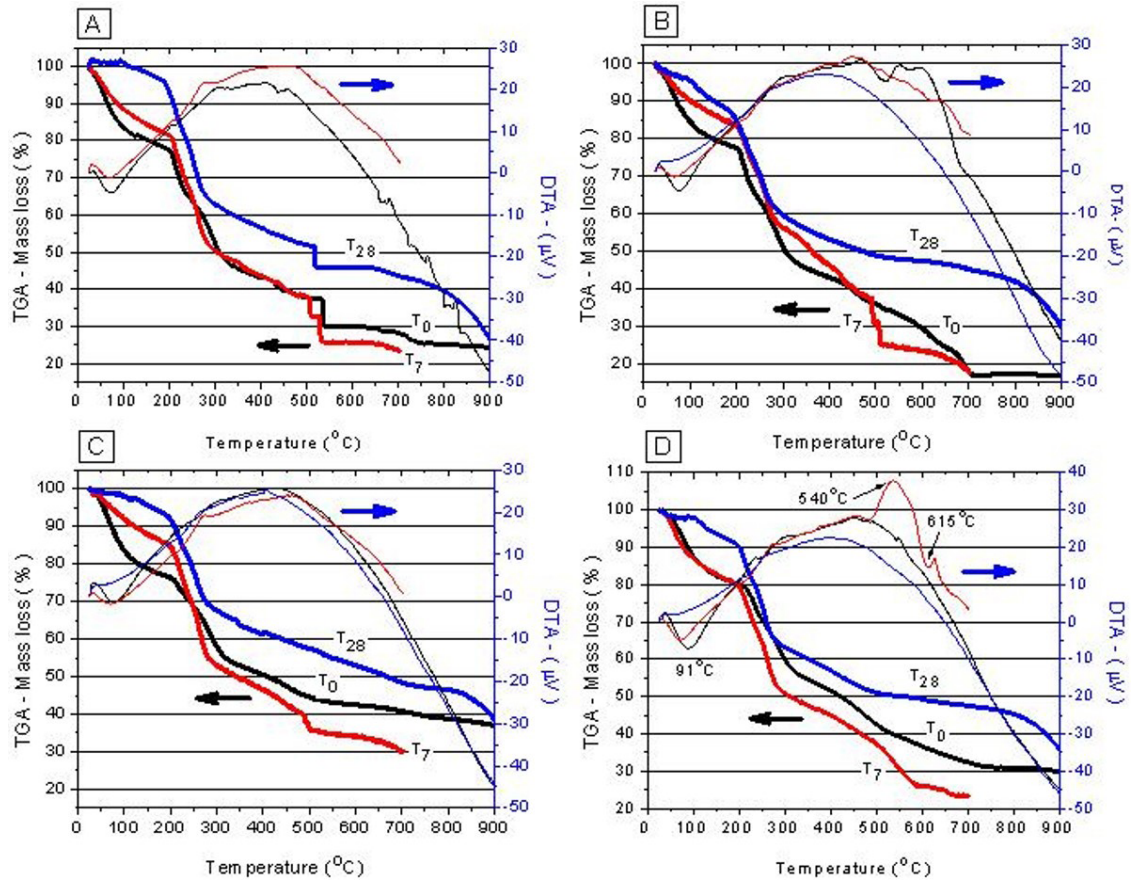

Figure 5. Thermal analysis results - DTA-TGA plots of (a) 100AS-0BG; (b) 75AS-25BG; (c) 50AS-50BG and (d) 25AS-75BG after incubation in SBF for times T0, T7 and T28 days.

when compared with samples from hybrids. The samples 75AS-25BG and 50AS-50BG had a progressive increase in precipitates and stability was reached for samples $25 \mathrm{AS}-75 \mathrm{BG}$, showing quantitative aspects similar from those of samples 50AS-50BG, as shown in the images in Figure 4.

\subsubsection{Thermal analysis by TGA/DTA}

As presented in Figure 5, the mass loss profile was considerably similar for all hydrogel compositions, where few differences were observed in their thermal decomposition behavior.
Thermal analysis of samples pre immersion in SBF showed mass losses in the temperature range of up to $200^{\circ} \mathrm{C}$ between 20 and $25 \%$, compatible with the dehydration of the samples ${ }^{57,58}$, as shown in Figure 5. The range between $200^{\circ} \mathrm{C}$ and $530^{\circ} \mathrm{C}$ indicated mass reduction around $47 \%$ for alginate beads and approximately between $31 \%$ and $43 \%$ for hybrid samples.

Although a significant reduction in mass loss would be expected for gradual reduction of polymer, according to Fiume et al. ${ }^{59}$ most of the mass reduction of glass can be 
attributed to residual water in the gel and decomposition of organic compounds of sol precursor. This can indicate that the reduction in polymer would be compensated to the same extent with higher levels of water associated on glass, that must justify the loss of mass with values very close for such temperature range.

Analogously, the results shown a similar trend associated with residues levels below of glass added. However, if the water content associated with glass on hydrogels is not considered in the calculation, it can found values agreed with the nominal composition.

From the DTA curves were verified an evident thermal event for samples $75 \mathrm{AS}-25 \mathrm{BG}$, in temperature ranging from 550 and $660^{\circ} \mathrm{C}$, which corresponds to the sintering zone of bioactive glasses ${ }^{60}$. Both results can be associated with the presence of glass network around the polymer matrix, without complex formation between silicon and alginate. The segregation can be confirmed by the surface texture on SEM images for samples with (25 wt.\%) glass.

The TGA curves revealed at 7 th and 28 th days posimmersion that the water content of samples had a gradual decrease until $200^{\circ} \mathrm{C}$, for an increase of immersion time. Moreover, the residual mass accounted had highest values associated with longer soaking time. Both results are associated to the manner for calculate the mass loss, where a number used as denominator (initial mass values of wet beads) varies from a higher value at time zero, to a smaller value with the increment in the soaking time (lower degree of hydration). Where hybrids, before immersion on SBF, may have a high degree of water coupling by the gel of glass incorporated on the composites ${ }^{59}$.
Mass reductions were also observed for TG curves at range of $800^{\circ} \mathrm{C}$ for all studied samples, which can be associated to conversion of the remaining materials to carbon residues and calcium carbonate ${ }^{61}$, which may suggest the significant presence of calcium based compounds after 28 days in SBF.

Regarding the analysis by DTA, similar behaviors were verified for all curves, with emphasis for samples with (25 wt.\%) and (75 wt.\%) of glass, immersed for up to 7 days, whose indicated exothermic peak at $540^{\circ} \mathrm{C}$ associated with the glass content in the material composition, that the literature ${ }^{62}$ identified to appear upon heat treatment of bioactive glasses at about $600^{\circ} \mathrm{C}$. For samples with ( $\left.50 \mathrm{wt} . \%\right)$ of glass, such peak is not observed, likely caused by several chemical interactions involving glass and alginate structure at the hybrid particles.

\subsubsection{Characterization by energy dispersion X-ray spectroscopy (EDS)}

A chemical analysis of EDS was carried out and the results are shown in the Table 3 and the graph inserted in Figure 6. The chemical elements $\mathrm{Si}, \mathrm{P}$, and Ca were identified and corresponding to the composition of bioactive glass.

At the 28th day it is possible to identify a peak related to sodium chloride (ICDD 9-432), that may have precipitated from the SBF solution, once time this solution has a high concentration of $\mathrm{Na}^{+}$and $\mathrm{Cl}^{-}$ions.

Percentage concentrations calculated for phosphorus, calcium and silicon, by dividing the concentration of each element by the total concentration of these three elements and multiplying by $100 \%$, demonstrated phosphorus and silicon were higher in all hybrids pos-immersion, while

Table 3. EDS compositional analysis performed on particles.

\begin{tabular}{|c|c|c|c|c|c|c|c|c|}
\hline \multirow{2}{*}{$\begin{array}{c}\text { Element } \\
(\%)\end{array}$} & \multicolumn{2}{|c|}{ 100AS-0BG } & \multicolumn{2}{|c|}{$75 \mathrm{AS}-25 \mathrm{BG}$} & \multicolumn{2}{|c|}{ 50AS-50BG } & \multicolumn{2}{|c|}{$25 \mathrm{AS}-75 \mathrm{BG}$} \\
\hline & $\mathrm{Ti}$ & $\mathrm{Tf}$ & $\mathrm{Ti}$ & $\mathrm{Tf}$ & $\mathrm{Ti}$ & $\mathrm{Tf}$ & $\mathrm{Ti}$ & $\mathrm{Tf}$ \\
\hline $\mathrm{C}$ & 29 & 32 & 39 & 24 & 22 & 21 & 23 & - \\
\hline $\mathrm{O}$ & 50 & 29 & 43 & 36 & 44 & 45 & 56 & 38 \\
\hline $\mathrm{Si}$ & - & - & 1 & 5 & 12 & 6 & 5 & 18 \\
\hline $\mathrm{Ca}$ & 15 & 9 & 10 & 6 & 14 & 20 & 11 & 7 \\
\hline $\mathrm{P}$ & - & 0 & 1 & 2 & 1 & 4 & 0 & 5 \\
\hline $\mathrm{Na}$ & - & 4 & - & 12 & - & 1 & - & 33 \\
\hline $\mathrm{Cl}$ & 6 & 27 & 6 & 14 & 7 & 4 & 5 & - \\
\hline
\end{tabular}
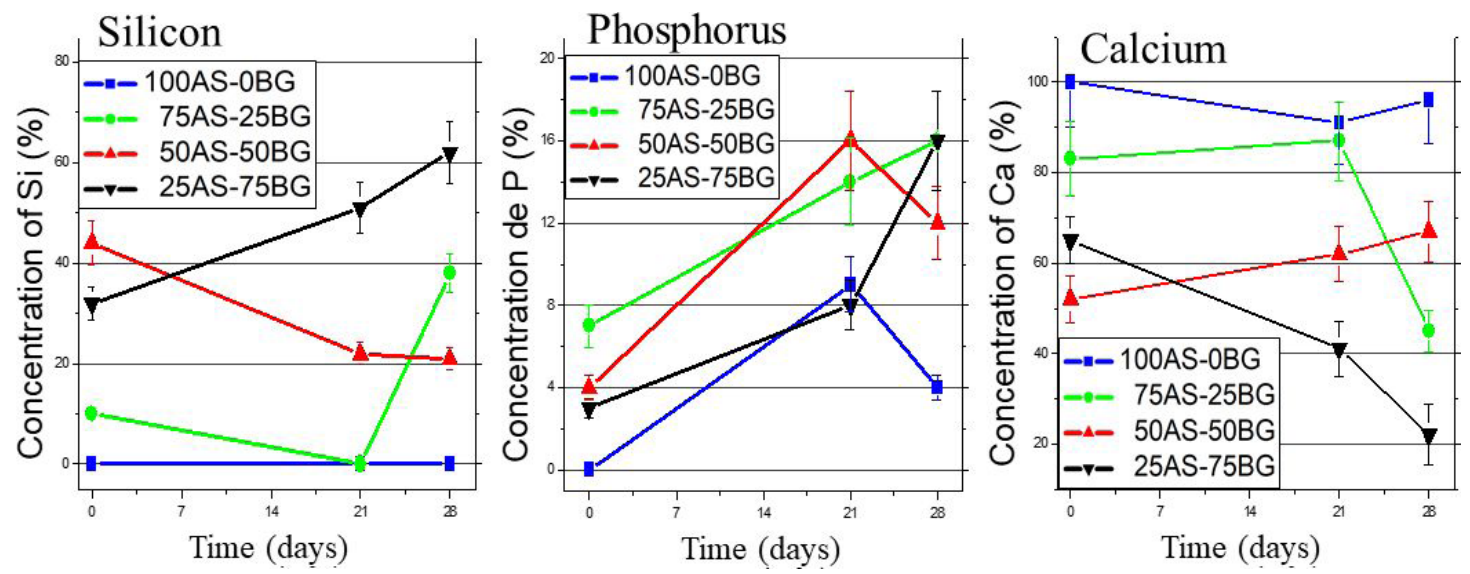

Figure 6. The change in the surface concentration of silicon, phosphorus, and calcium over time after hydrogels immersion in SBF. 
calcium necessary was lower to result in a sum of $100 \%$ (Figure 6). However, even after immersion considerable levels of calcium were observed.

Exception was observed for hybrids 50AS-50BG with higher levels of calcium, fewer silicon levels whereas phosphorus had similar behavior of other compositions, always for pos-immersion samples.

\subsubsection{Chemical characterization of hydrogels by FTIR spectroscopy}

The FTIR analysis comparing samples before and after immersion in SBF are shown in Figure 7. For FTIR spectra of $100 \mathrm{AS}-0 \mathrm{BG}$ samples, it was verified that the band at $3500 \mathrm{~cm}^{-1}$ associated with $\mathrm{OH}$ groups, has its intensity increased after one week of immersion, followed by decrease with 28 days. These changes may indicate a high initial ratio of alginate degradation in the initial 7 days, especially for regions with lower degree of cross-linking by the calcium ions. Therefore, residual structure of samples upon SBF soaking for 28 days must correspond to the portion of alginate with a high degree of gelation ${ }^{63,64}$, which limits the polymer chains ability to bind water molecules ${ }^{65}$, as they have fewer carboxylate groups. These observations also can be associated with EDS results, which shows that amount of $\mathrm{Ca}$ decrease at 7 days of immersion and increased after 28 days. Furthermore, it can be verified a reduction followed by an increase in the bands at 1600 and $1400 \mathrm{~cm}^{-1}$ of $\mathrm{COO}^{-}$groups and by the same oscillation for the rate of volatiles observed in thermogravimetric analysis, which can be associates to the fewer loss mass of organic phase.

Regarding intensity of bands 1030 and $1070 \mathrm{~cm}^{-1}$, a progressive increase was observed for the periods of 7 and 28 days. This result may be associated with phosphate precipitation, which is also confirmed by an increase in phosphorus observed in EDS. A speculation for this event may be associated with large amount of calcium available from alginate gelation, where it can increase the precipitation of phosphates for 7 days, following the same behavior for 28 days. The high precipitation of salts may explain the reduction at $\mathrm{OH}, \mathrm{COO}^{-}$and $\mathrm{COOH}$ bands, as well as the maintenance in the intensity of the band in $1070 \mathrm{~cm}^{-1}$, and the appearance of the band centered at 780 and $600 \mathrm{~cm}^{-1}$.

At the opposite extreme, samples with (75 wt.\%) BG showed high intensity for the 3500 bands; $1600 ; 1400 ; 1080$; $1030 ; 950 ; 820 ; 600$ and $560 \mathrm{~cm}^{-1}$ meanwhile there were a reduction in all these bands after 7 days. For 28 days immersion a decrease of $3500 \mathrm{~cm}^{-1}$, stability of $1600 \mathrm{~cm}^{-1}$ and an increase for bands 1400, 1030 and $950 \mathrm{~cm}^{-1}$ were observed, which may suggest the presence of bioactive glass combined with the polymer. In addition to these findings, a tendency for the presence of phosphate was also supported by EDS analysis.

For samples with (75 wt.\%) AS the FTIR spectra posimmersion in SBF at times of 0 and 7 days were practically the same, with exception for a less intense band at $3500 \mathrm{~cm}^{-1}$ for the period of 7 days. Compared to samples of $100 \%$ AS, all bands for ( $75 \mathrm{wt} . \%$ ) AS samples were less intense. Increase in the bands of these samples was observed at 28 days, and the vibrations 1020,820 and $600 \mathrm{~cm}^{-1}$ showed increases significantly higher than those of the other vibrations, which may indicate the presence of the glass stabilizing the structure of material ${ }^{4,52}$.

Similar characteristics regarded for the samples with (50 wt.\%) AS were showed in FTIR at 0 and 7 days, including their intensities. After 28 days of immersion in SBF all bands increased slighty, including the $3500 \mathrm{~cm}^{-1}$. Hence, the suggestion is that the glass may have physically blocked the polymer, results that can be supported by SEM images, with the presence of aligned polymer structures, as shown in Figure $7 \mathrm{~b}$ and represented by scheme of Figure 8.

Considering FTIR characterization and the SEM images of Figure $7 \mathrm{a}$, it is found particles of $100 \%$ alginate of flat and smooth surface covered with precipitates, samples of (25 wt.\%) of AS resulting in a glass structure with polymeric incrustations and samples with (50 wt.\%) of AS revealed grooves of polymers associated with fine particulate, suggesting also the interaction between the materials, as shown in Figure 7c.

Silica-alginate hybrid hydrogels prepared by a solgel were also performed by Hernández-González et al. ${ }^{43}$. The authors observed that silica nuclei grown through the surface and inner face of the alginate matrix. In addition, the catalyst absence favored an interpenetrated silica/alginate network in which the alginate structure was preserved, and the polycondensation of $\mathrm{Si}-\mathrm{OH}$ groups took place within this structure resulting in a better distribution in the hybrid structure.

Thus, the samples with (50 wt.\%) AS obtained in our work, which represents intermediate levels of silica should limit the growth of glasses in the alginate matrix. In addition, the alginate content of these hybrids may be sufficient to restrict the growth of the glass nuclei. These results may indicate a composition of matrix capable to act as of bioactive glass reservoir, modulating its degradation and function as support for cells growth.

\subsubsection{Crystallinity and phase characterization by $X$-ray diffraction}

Figure 9-II present the XRD patterns of alginate spheres cross linked with calcium at 0 and 28 days of immersion in SBF solution media. The XRD patterns of the hydrogels before immersion revealed a broad diffraction bands, which is typically associated with guluronic acid blocks at $15^{\circ}$ and manuronic acid blocks at $22^{\circ} 66-68$. It can be observed that diffractograms of hybrids based on alginate with bioactive glass start to present a reduction on peak intensity mainly for adding of $25 \%$ glass (Figure 9-III). In addition, a slight reduction in both peaks at 15 and $22^{\circ}$ were observed for the other glass concentrations, whose diffractograms were not inserted, but which showed a similar aspect between them, indicating the contributions from alginate with semi-crystalline structure $^{69}$ and amorphous phase of bioactive glass, as found by Fiume et al. ${ }^{59}$ for glasses obtained by the sol-gel process. This result suggests that glass phase was well dispersed in the alginate matrix ${ }^{43}$.

Conversely, the results of XRD diffraction of all hydrogels (Figure 9) after 28 days of SBF assay presented peaks at $27^{\circ}$, $32^{\circ}, 45^{\circ}, 57^{\circ}, 66^{\circ}$ and $75^{\circ}$, which evidenced the formation of new crystalline phases and values matched well with the standard ICDD reference pattern 9-432. According to the 

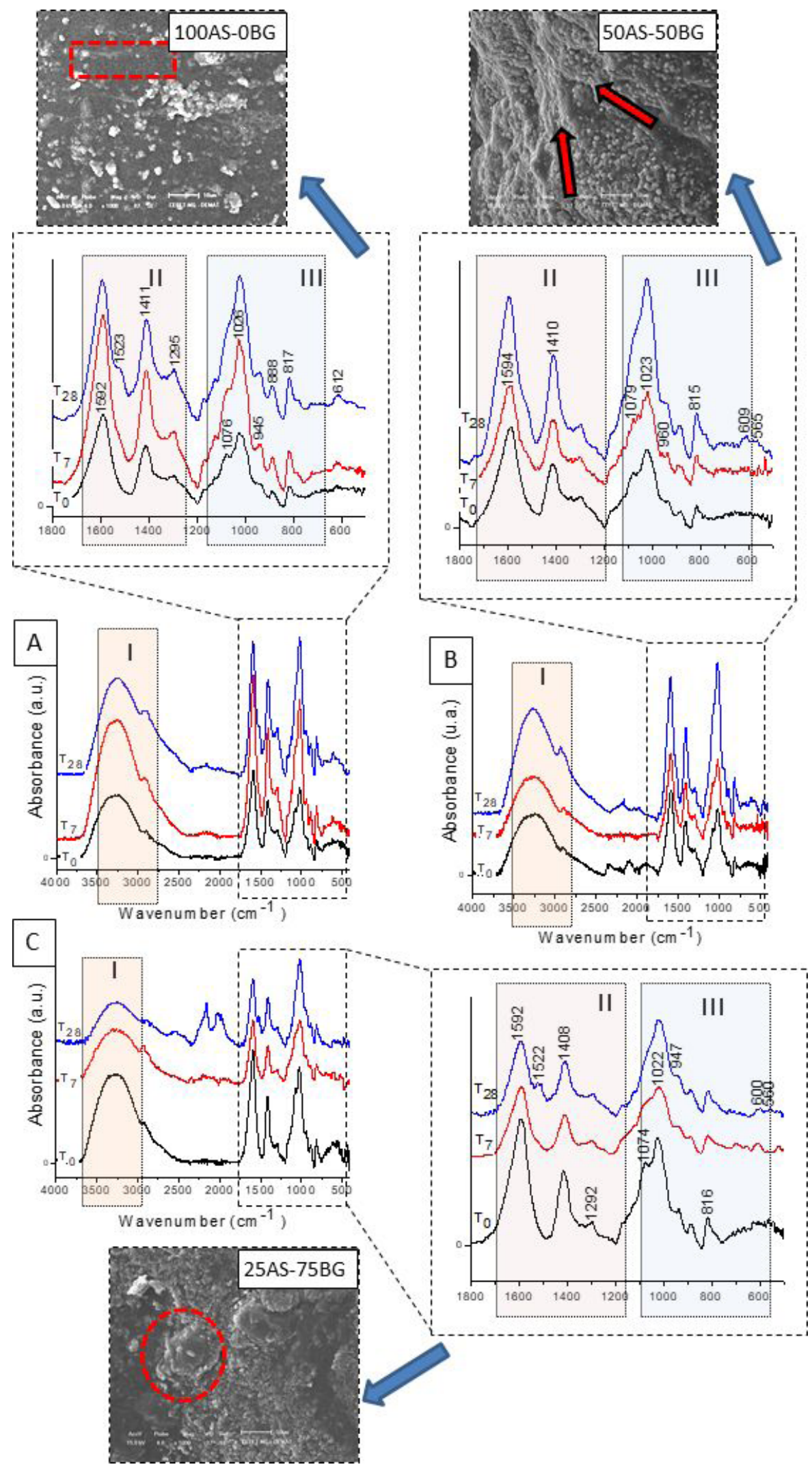

Figure 7. FTIR spectra of surfaces of the samples (a) 100AS-0BG, (b) 50AS-50BG and (c) 25AS-75BG after incubation in SBF for times T0, T7 and T28 days. Details of FTIR spectra for selected regions: (I) - (2800-3500 $\left.\mathrm{cm}^{-1}\right)$; (II) $-\left(1200-1750 \mathrm{~cm}^{-1}\right)$ and (III) $-\left(600-1100 \mathrm{~cm}^{-1}\right)$. SEM analysis of hybrids (at magnification 1000x) presented in details showed in rectangle of (a) thin striation; arrows of (b) grooves of aligned polymer structures and circles of (c) polymeric incrustations. 
literature, the appearance of these peaks can be associated with sodium chloride ${ }^{70}$ resulting from the precipitation of SBF salts during the drying of samples.
Although several peaks associated with sodium chloride can be overlapping with calcium phosphate compounds, the inserts of Figure 9-III show details of the peaks localized

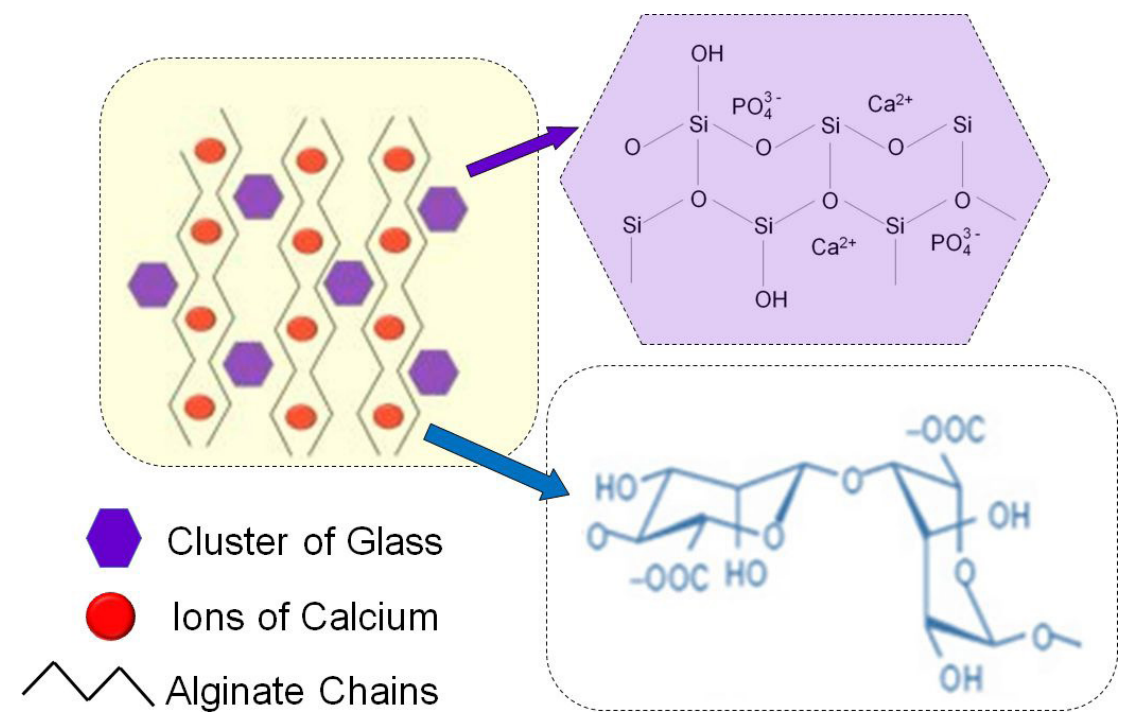

Figure 8. Representation of the complex in hybrids based on AS/BG.
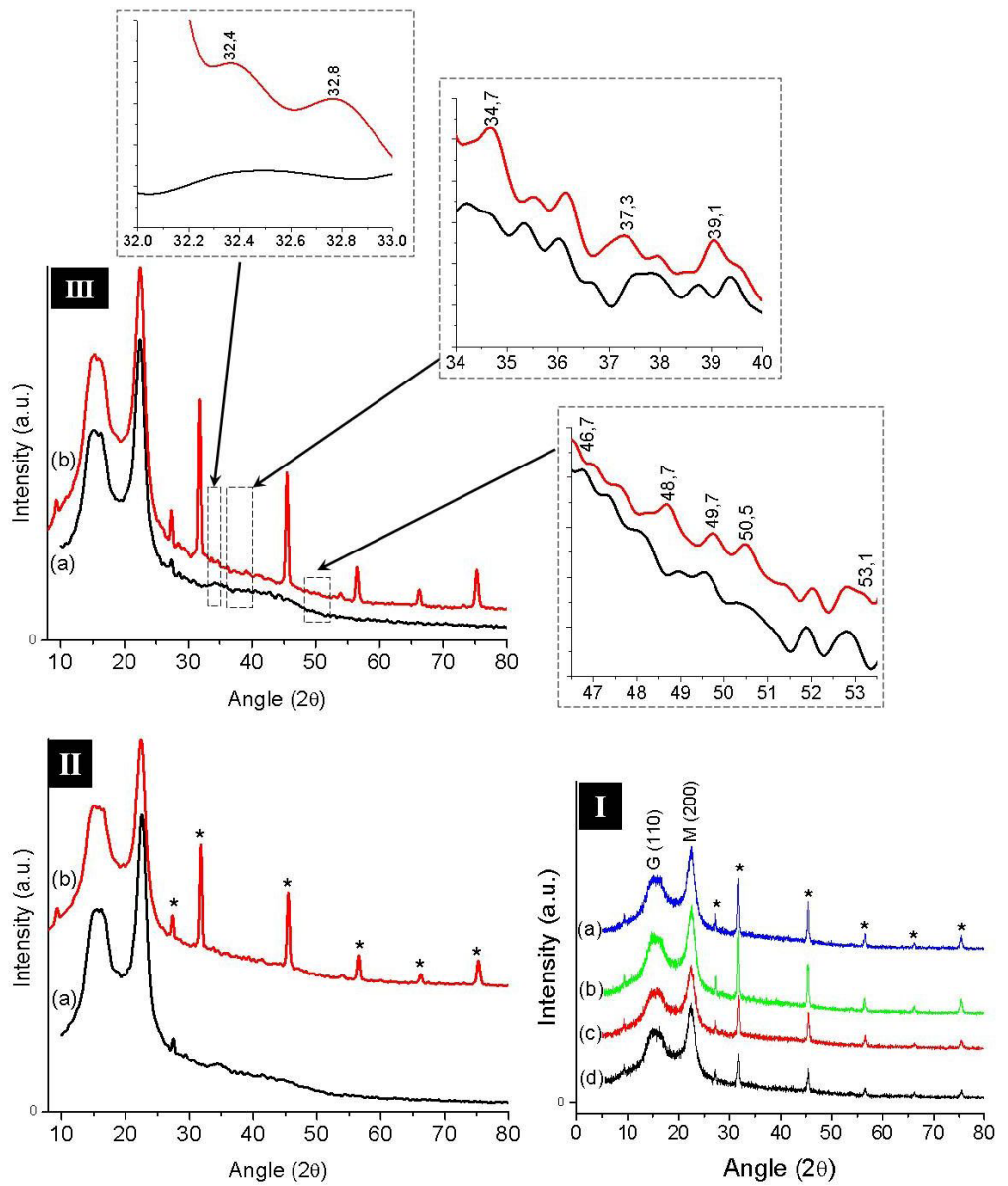

Figure 9. XRD pattern shown in (I) for samples of (a) 100AS-0BG; (b) 75AS-25BG; (c) 50AS-50BG and (d) 25AS-75BG after incubation in SBF for 28 days; (II) and (III) showing XRD respectively of samples 100AS-0BG and 75AS-25BG, for (a) before and (b) after soaking in SBF solution by 28 days. Details on dashed rectangles of III showing magnified diffractograms for main calcium phosphate regions. 
at $32.4,32.8,39.1$, and $50.5^{\circ}$ that are consistent with hydroxyapatite ${ }^{71}$.

\section{Conclusion}

Alginate/bioactive glass particles in desired size and spherical shape were successfully obtained with varying structural properties for different concentration of glass added.

The processing route used for synthesizing the inorganicorganic hybrids controlling gelling temperature was able to have incorporated the elements $\mathrm{Si}, \mathrm{Ca}$ and $\mathrm{P}$ that play a special role in bioactivity.

Samples were analyzed by studying the surface of the beads with SEM, EDS, FTIR and XRD after they have been immersed in the SBF for some time. Even upon soaking into SBF for 28 days, the structure of beads remains with your surface available to interact with chemical compounds of medium that can significantly favored apatite deposition with increasing immersion time in SBF. As shown on the surfaces with some precipitate, which are formed by small crystalline aggregates.

Between the compositions of beads, we can propose as better the sample with (50 wt.\%) AS. Although these samples have intermediate levels of glass in their composition, such ratio of bioactive glass based gel compared to alginate demonstrated ability to maintain the sphere shape. In addition, (50 wt.\%) AS beads seems do not inhibits the activity of glass, where could be observed gradual reduction in silicon levels and progressive increase in phosphate and mainly the calcium levels during SBF tests. The results were also confirmed by phosphate groups at FTIR and by precipitates showed in SEM images.

Thereby, the modifications in the hybrids features from surface erosion include the partially degradation due to polymer disentanglements forming some products which may diffuse outwards. Moreover, the inorganic components may also be degraded which can provide controlled release of ionic specimens to act as potential use in bone repair, particularly to low-load or nonload bearing applications.

\section{Acknowledgements}

The authors would like to acknowledge to National Council for Scientific and Technological Development (CNPq), Coordination for the Improvement of Higher Education Personnel (CAPES) and Foundation for the Support to the Researches in Minas Gerais (FAPEMIG) for their financial support on this project; the Federal Center for Technological Education of Minas Gerais (CEFET-MG) and your Department of Materials Engineering (DEMAT) for providing the equipment and technical cooperation for this paper.

\section{Reference}

1. Hench LL. Bioceramics: from concept to clinic. J Am Ceram Soc. 1991;74(7):1487-510.

2. Hench LL. Opening paper 2015- some comments on bioglass: four eras of discovery and development. Biomed Glasses. 2015;1(1):1-11.

3. Krishnan V, Lakshmi T. Bioglass: a novel biocompatible innovation. J Adv Pharm Technol Res. 2013;4(2):78-83.
4. Pereira MM, Jones JR, Orefice RL, Hench LL. Preparation of bioactive glass-polyvinyl alcohol hybrid foams by the sol-gel method. J Mater Sci Mater Med. 2005;16(11):1045-50.

5. Yue S, Lee PD, Poologasundarampillai G, Jones JR. Evaluation of 3-D bioactive glass scaffolds dissolution in a perfusion flow system with X-ray microtomography. Acta Biomater. 2011;7(6):2637-43.

6. Zeng Q, Han Y, Li H, Chang J. Bioglass/alginate composite hydrogel beads as cell carriers for bone regeneration: bg/ alg composite hydrogel beads. J Biomed Mater Res B Appl Biomater. 2014;102(1):42-51.

7. Gestel NA, Geurts J, Hulsen DJ, Rietbergen BV, Hofmann S, Arts JJ. Clinical applications of S53P4 bioactive glass in bone healing and osteomyelitic treatment: a literature review. BioMed Res Int. 2015;2015:1-12.

8. Douglas DT, Dziadek M, Schietse J, Boone M, Declercq HA, Coenye T, et al. Pectin-bioactive glass self-gelling, injectable composites with high antibacterial activity. Carbohydr Polym. 2018;205(1):427-36.

9. Hench LL. The story of bioglass ${ }^{\circledR}$. J Mater Sci Mater Med. 2006; 17:967-78.

10. Jones JR. Review of bioactive glass: From Hench to hybrids. Acta Biomater. 2013;9(1):4457-86.

11. Deshmukh K, Kovaric T, Krenek T, Docheva D, Stich T, Pola J. Recent advances and future perspectives of sol-gel derived porous bioactive glasses: a review. $\mathrm{R}$ Soc Chem Adv. 2020;10:33782-835.

12. Carvalho SM, Moreira CD, Oliveira AC, Oliveira AA, Lemos EM, Pereira MM. Bioactive glass nanoparticles for periodontal regeneration and applications in dentistry. In: Subramani K, Ahmed W, editors. Nanobiomaterials in clinical dentistry. 2nd ed. Amsterdam: Elsevier; 2019. p. 351-82.

13. Taygun ME, Boccaccini AR. Nanoscaled bioactive glass particles and nanofibers. In: Ylänen $\mathrm{H}$, editor. Bioactive glasses materials, properties and applications. 2nd ed. Amsterdam: Elsevier; 2017. p. 235-23.

14. Li H, Wu X, Yang B, Li J, Xu L, Liu H, et al. Evaluation of biomimetically synthesized mesoporous silica nanoparticles as drug carriers: structure, wettability, degradation, biocompatibility and brain distribution. Mater Sci Eng C. 2019;94(1):453-64.

15. Draenerta ME, Draenerta Y, Draenerta K, Pohlemannc T, Erlerd M. Formación de hueso esponjoso con esferas microcompartimentales. Rev Esp Cir Ortop Traumatol. 2014;58(3):131-7.

16. Asaoka T, Ohtake S, Furukawa KS, Tamura A, Ushida T. Development of bioactive porous $\alpha$-TCP/HAp beads for bone tissue engineering. J Biomed Mater Res A. 2013;101(11):3295300.

17. Miyauchi S, Furukawa KS, Umezu Y, Ozeki Y, Ushida T, Tateishi T. Novel bone graft model using bead-cell sheets composed of tricalcium phosphate beads and bone marrow cells. Mater Sci Eng C. 2004;24:875-9.

18. Moreira AP, Sader MS, Soares GD, Leão MH. Strontium incorporation on microspheres of alginate/ $\beta$-tricalcium phosphate as delivery matrices. Mater Res. 2014;17(4):967-73.

19. Zhang J, Xiao D, He X, Shi F, Luo P, Zhi W, et al. A novel porous bioceramic scaffold by accumulating hydroxyapatite spheres for large bone tissue engineering. III: characterization of porous structure. Mater Sci Eng C. 2018;89:223-9.

20. Agarwal T, Kabiraj P, Narayana GH, Kulanthaivel S, Kasiviswanathan U, Pal K, et al. Alginate bead based hexagonal close packed 3d implant for bone tissue engineering. ACS Appl Mater Interfaces. 2016;8(47):32132-45.

21. Silva GA, Coutinho OP, Ducheyned P, Shapiroe IM, Reisa RL. The effect of starch and starch-bioactive glass composite microparticles on the adhesion and expression of the osteoblastic phenotype of a bone cell line. Biomaterials. 2007;28(2):326-34

22. Moreira CD, Carvalho SM, Florentino RM, França A, Okano BS, Rezende CM, et al. Injectable chitosan/gelatin/bioactive glass 
nanocomposite hydrogels for potential bone regeneration: in vitro and in vivo analyses. Int J Biol Macromol. 2019;132(1):811-21.

23. Ren H, Cuia Y, Lia A, Qiu D. Bioactive glass sol as a dual function additive for chitosan-alginate hybrid scaffold. Chin Chem Lett. 2018;29:395-8.

24. Konur $\mathrm{O}$. The pioneering research on the wound care by alginates. In: Konur O, editor. Handbook of algal science, technology and medicine. Amsterdam: Elsevier; 2020. p. 467-81.

25. Paques JP, Linden EV, Rijn CJ, Sagis LM. Preparation methods of alginate nanoparticles. Adv Colloid Interface Sci. 2014;209:163-71.

26. Pawar SN, Edgar KJ. Alginate derivatization: a review of chemistry, properties and applications. Biomaterials. 2012;33(11):3279305.

27. Dalheim MØ, Vanacker J, Najmi MA, Aachmann FL, Strand BL, Christensen BE. Efficient functionalization of alginate biomaterials. Biomaterials. 2016;80:146-56.

28. Lee KY, Mooney DJ. Alginate: properties and biomedical applications. Prog Polym Sci. 2012;37(1):106-26.

29. Venkatesan J, Bhatnagar I, Manivasagan P, Kang KH, Kim SK. Alginate composites for bone tissue engineering: a review. Int J Biol Macromol. 2015;72:269-81.

30. Vueva Y, Connell LS, Chayanun S, Wang D, McPhail DS, Romer F, et al. Silica/alginate hybrid biomaterials and assessment of their covalent coupling. Applied Materials Today. 2018;11:1-12.

31. Mansur HS, Costa HS. Nanostructured poly(vinyl alcohol)/ bioactive glass and poly(vinyl alcohol)/chitosan/bioactive glass hybrid scaffolds for biomedical applications. Mater Sci Eng C. 2012;32(3):404-15.

32. Costa HS, Mansur AP, Pereira MM, Mansur HS. Engineered hybrid scaffolds of poly(vinyl alcohol)/bioactive glass for potential bone engineering applications: synthesis, characterization, cytocompatibility, and degradation. J Nanomater. 2012;2012:116.

33. Dias MR, Leão RC, Costa HS. Obtenção e caracterização de microesferas de alginato/vidro bioativo. Perspectiv Cienc Tecnol. 2020;12:122-37.

34. Kokubo T, Takadama H. How useful is SBF in predicting in vivo bone bioactivity? Biomaterials. 2006;27(15):2907-15.

35. Patel YL, Sher P, Pawar AP. The effect of drug concentration and curing time on processing and properties of calcium alginate beads containing metronidazole by response surface methodology. AAPS PharmSciTech. 2006;7(4):E24-30.

36. Liu T, Yi S, Liu G, Hao X, Du T, Chen J, et al. Aqueous twophase emulsions-templated tailorable porous alginate beads for 3D cell culture. Carbohydr Polym. 2021;258:117702.

37. Chang BS, Lee CK, Hong KS, Youn HJ, Ryu HS, Chung SS, et al. Osteoconduction at porous hydroxyapatite with various pore congurations. Biomaterials. 2000;21:1291-8.

38. Loh QL, Choong C. Three-dimensional scaffolds for tissue engineering applications: role of porosity and pore size. Tissue Eng Part B Rev. 2013;19(6):485-502.

39. Hung D, Liu Z, Shah N, Hao Y, Searson PC. Finite size effects in ordered macroporous electrodes fabricated by electrodeposition into colloidal crystal templates. J Phys Chem C. $2007 ; 111(8): 3308-13$.

40. Lee BB, Ravindra P, Chan ES. Size and shape of calcium alginate beads produced by extrusion dripping. Chem Eng Technol. 2013;36(10):1627-42.

41. Sathain A, Monvisade P, Siriphannon P. Bioactive alginate/ carrageenan/calcium silicate porous scaffolds for bone tissue engineering. Materials Today Communications. 2021;26:102165.

42. Zamani D, Moztarzadeh F, Bizari D. Alginate-bioactive glass containing $\mathrm{Zn}$ and $\mathrm{Mg}$ composite scaffolds for bone tissue engineering. Int J Biol Macromol. 2019;137:1256-67.

43. Hernández-González AC, Téllez-Jurado L, Rodríguez-Lorenzob LM. Synthesis of in-situ silica-alginate hybrid hydrogels by a sol-gel route. Carbohydr Polym. 2020;250:116877.
44. Laia AG. Estudo de filmes e hidrogéis a base de alginato e goma gelana visando aplicações na regeneração de discos intervertebrais [dissertation]. Belo Horizonte: Federal Center for Technological Education of Minas Gerais; 2015.

45. Bajpai SK, Sharma S. Investigation of swelling/degradation behaviour of alginate beads crosslinked with $\mathrm{Ca} 2+$ and $\mathrm{Ba} 2+$ ions. React Funct Polym. 2004;59(2):129-40.

46. Paula HC, Oliveira EF, Abreu FO, Paula RC, Moraes SM, Forte MM. Esferas (beads) de alginato como agente encapsulante de óleo de croton zehntneri Pax et Hoffm. Polímeros. 2010;20(2):11220.

47. Hammouda SB, Aadhoum N, Monser L. Chemical oxidation of a malodorous compound, indole, using iron entrapped in calcium alginate beads. J Hazard Mater. 2016;301:350-61.

48. Almeida RM, Pantano CG. Structural investigation of silica gel films by infrared spectroscopy. J Appl Phys. 1990;68:1225-32.

49. Román J, Padilla S, Vallet-Regí M. Sol-gel glasses as precursors of bioactive glass ceramics. Chem Mater. 2003;15:798-806.

50. Martin AI, Salinas AJ, Vallet-Regi M. Bioactive and degradable organic-inorganic hybrids. J Eur Ceram Soc. 2005;25:3533-8.

51. Nooeaid P, Li W, Roether JA, Mouriño V, Goudouri OM, Schubert DW, et al. Development of bioactive glass based scaffolds for controlled antibiotic release in bone tissue engineering via biodegradable polymer layered coating. Biointerphases. 2014;9(4):041001.

52. Silva Júnior PE, Oréfice RL. Compósitos bioativos obtidos a partir da inserção de vidro bioativo em matriz de poli(metacrilato de metila). Polímeros. 2001;11(3):109-15.

53. Vargas PO, Pereira NR, Guimarães AO, Waldman WR, Pereira VR. Shrinkage and deformation during convective drying of calcium alginate. Lebensm Wiss Technol. 2018;97:213-22.

54. Mansur HS, Costa HS, Mansur AA, Pereira MM. 3D-macroporous hybrid scaffolds for tissue engineering: network design and mathematical modeling of the degradation kinetics. Mater Sci Eng C. 2012;32(3):404-15.

55. Park JH, Lee EJ, Knowles JC, Kim HW. Preparation of in situ hardening composite microcarriers: calcium phosphate cement combined with alginate for bone regeneration. J Biomater Appl. 2014;28(7):1079-84.

56. Günter EA, Popeyko OV, Belozerov VS, Martinson EA, Litvinets SG. Physicochemical and swelling properties of composite gel microparticles based on alginate and callus cultures pectins with low and high degrees of methylesterification. Int J Biol Macromol. 2020;164:863-70.

57. Nawaz Q, Pablos-Martín A, Silva JM, Hurle K, Jaimes AT, Brauer DS, et al. New insights into the crystallization process of sol-gel-derived 45S5 bioactive glass. J Am Ceram Soc. 2020;103:4234-47.

58. Yang N, Wang R, Rao P, Yan L, Zhang W, Wang J, et al. The fabrication of calcium alginate beads as a green sorbent for selective recovery of $\mathrm{Cu}(\mathrm{II})$ from metal mixtures. Crystals. 2019;9(5):255.

59. Fiume E, Migneco C, Verné E, Baino F. Comparison between bioactive sol-gel and melt-derived glasses/glass-ceramics based on the multicomponent $\mathrm{SiO}_{2}-\mathrm{P}_{2} \mathrm{O}_{5}-\mathrm{CaO}-\mathrm{MgO}-\mathrm{Na}_{2} \mathrm{O}-\mathrm{K}_{2} \mathrm{O}$ system. Materials. 2020;13(3):540.

60. Delben JR, Pereira K, Oliveira SL, Alencar LD, Hernandes AC, Delben AA. Bioactive glass prepared by sol-gel emulsion. J Non-Cryst Solids. 2013;361:119-23.

61. Nawaz Q, Martín PA, Silva JM, Berthold L, Hurle K, Jaimes AT, et al. Crystallization study of sol-gel derived 13-93 bioactive glass powder. J Eur Ceram Soc. 2021;41(2):1695-706.

62. Lefebvre L, Gremillard L, Chevalier J, Zenati R, BernacheAssolant D. Sintering behaviour of $45 \mathrm{~S} 5$ bioactive glass. Acta Biomater. 2008;4:1894-903.

63. Thomas A, Johnson E, Agrawal AK, Bera J. Preparation and characterization of glass-ceramic reinforced alginate scaffolds for bone tissue engineering. J Mater Res. 2019;34(22):3798-809. 
64. Burdick JA, Chung C, Jia X, Randolph MA, Langer R. Controlled degradation and mechanical behavior of photopolymerized hyaluronic acid networks. Biomacromolecules. 2005;6(1):386-91.

65. Jin L, Hong YC, Pyo JW, Song H, Kang JY, Lee SW, et al. Monitoring of swelling and degrading behavior of alginate beads using optical tweezers. Biochip J. 2009;3(3):213-8.

66. Fernandes RS, Moura MR, Aouada FA. Otimização da síntese de hidrogéis nanocompósitos intercalados para possível aplicação na área médica. Quim Nova. 2016;40(1):60-7.

67. Sundarrajan P, Eswaran P, Marimuthu A, Subhadra LB, Kannaiyan P. One pot synthesis and characterization of alginate stabilized semiconductor nanoparticles. Bull Korean Chem Soc. 2012;33(10):3218-24.
68. Liu J, Zhang O, Wu Z, Wu J, Li J, Huang L, et al. A highperformance alginate hydrogel binder for the $\mathrm{Si} / \mathrm{C}$ anode of a Li-ion battery. Chem Commun. 2014;50(48):6386-9.

69. Helmiyati AM. Characterization and properties of sodium alginate from brown algae used as an ecofriendly superabsorbent. IOP Conf Series Mater Sci Eng. 2017;188(1):012019.

70. Barauna JB, Pereira CS, Gonçalves IA, Vitoriano JO, Junior CA. Sodium chloride crystallization by electric discharge in brine. Mater Res. 2017;20(2):215-20.

71. Souza IE, Carvalho SMT, Pereira MM. Fluorine-containing bioactive glass spherical particles synthesized by sol-gel route assisted by ultrasound energy or mechanical mixing. Mater Res. 2020;23(3):1-13. 